\title{
Implantação de uma aromateca de óleos essenciais em uma biblioteca especializada
}

\author{
Implementation of an "aromateca" with essential oils in a specialized library
}

\begin{abstract}
Marcelo Cavaglieri
Mestre em Gestão de Unidades de Informação pela Universidade do Estado de Santa Catarina - UDESC. Bibliotecário do Senac Saúde e Beleza. E-mail: marceloglieri@yahoo.com.br
\end{abstract}

Tamara de Souza Padilha Pós-graduanda em Tecnologias na Aprendizagem pelo Centro Universitário Senac São Paulo. Auxiliar de Biblioteca no Senac Saúde e Beleza E-mail: tamarasp@@hotmail.com

Jorge Moisés Kroll do Prado Doutorando em Ciência da Informação pela Universidade Federal de Santa Catarina - UFSC. Coordenador da Rede de Bibliotecas do Senac Santa Catarina.

E-mail: jorge.exlibris@gmail.com

\section{Resumo}

O objetivo deste estudo é descrever a formação da Aromateca Saúde \& Beleza de óleos essenciais e vegetais pela equipe da Biblioteca do Senac Saúde e Beleza em Florianópolis. Apresenta-se uma fundamentação teórica a respeito de como surgiram os óleos essenciais, como é realizada sua extração, modos e técnicas de aplicação, algumas contraindicações que devem ser observadas e seus benefícios para saúde, bem-estar e beleza. A criação deste espaço se justifica principalmente pela colaboração com a instituição de permitir aliar a prática com a teoria no processo de ensino e de aprendizagem, disponibilizando uma nova fonte de informação para que o público acadêmico possa suprir suas necessidades informacionais. Os resultados têm sido gratificantes, pois o retorno positivo dos professores e estudantes demonstra o efeito benéfico que uma nova fonte de informação pode ter na vida dos profissionais, contribuindo de forma significativa para sua formação.

Palavras-chave: Aromateca. Óleos essenciais. Óleos vegetais. Aromaterapia. Senac Saúde e Beleza.

\begin{abstract}
The aim of this study is to describe the creation of "Aromateca" Health \& Beauty with essential and vegetable oils for the team of Library in Senac Saúde e Beleza in Florianópolis. A theoretical foundation is presented about as to how came the essential oils, how is realized its extraction, modes and techniques to application. The justification of creating this space is primarily for collaboration with the institution to allow combine practice and theory in the process of teaching and learning, providing a new source of information for the academic community to meet their information needs. The results have been rewarding because the positive feedback from teachers and students shows the beneficial effects that a new source of information can have in the lives of professionals, contributing significantly to their training.
\end{abstract}

Keywords: “Aromateca”. Essentials oil. Vegetables oil. Aromatherapy. Senac Saúde e Beleza. 


\section{Introdução}

Os óleos essenciais são utilizados pela humanidade há milênios de anos, para purificação do corpo, por meio de banhos, rituais de beleza e afins, e para purificação do seu espírito e de seus ancestrais, mediante rituais religiosos. Posteriormente, foram incluídos também como fonte terapêutica natural para cura e alívio de dores e doenças.

Os óleos essenciais são constituídos de pequenas glândulas que estão presentes em cada elemento da planta - no caule, folha, fruto, casca ou na flor. Na natureza, os óleos essenciais são liberados naturalmente, porém, para sua extração artificial, é necessário romper estas glândulas, seja aquecendo-as ou esmagando-as (BOORHEM, 1997). A extração dos óleos essenciais pode ocorrer de maneiras diferentes (prensagem ou pressão a frio, enfloragem, maceração, extração por solvente, destilação a vapor e a vácuo), sendo que cada método usufrui de uma forma para extrair o óleo da planta ou de sua composição, do melhor modo a fim de aproveitá-lo próximo de sua totalidade (SILVA, 2001).

O uso dos óleos pode ser feito de maneiras diferentes, com finalidades variadas. Boorhem (1997) menciona que os óleos são mais utilizados em tratamentos de massagem corporais. Na pele, o óleo é absorvido pelos líquidos do corpo e pelo sangue, atuando internamente. Porém, é possível utilizá-los acrescidos à agua do banho, com compressas ou inalados - sendo que este método tem uma ação mais rápida, devido à comunicação direta dos órgãos do olfato com o cérebro.

A Aromateca Saúde \& Beleza de óleos essenciais surgiu para atender sobretudo aos estudantes dos cursos de massoterapia, estética, podologia e manicure, que estudam tais óleos dentro de sua grade curricular, mas que nem sempre tinham acesso a uma diversidade de produtos para uso didático. Além disso, tendo a educação por competências como estratégia de ensino, é importante que o aluno tenha contato com outras informações que não as bibliográficas somente, enaltecendo um espaço interativo e colaborativo para a qualificação profissional. Assim, o objetivo deste texto é o de descrever como foi formada a aromateca de óleos essenciais e vegetais pela equipe da Biblioteca do Senac Saúde e Beleza. A criação é observada como um caso, logo, nos atribuímos da metodologia de estudo de caso que, segundo Yin (2010), permite descrever de maneira longitudinal, individual e qualitativamente.

Por intermédio da aromateca, é possível conhecer os aromas de 18 óleos essenciais de plantas variadas. Alguns exemplos são os óleos essenciais de erva doce, de citronela, de cravo, 
de grapefruit e de lemongrass. Além disso, encontram-se 8 óleos vegetais, também denominados de óleos carreadores ou óleo base, que são utilizados como intermediadores dos óleos essenciais para aplicação direta na pele. $\mathrm{Na}$ aromateca, dispõe-se de óleos vegetais como argan, jojoba, rosa mosqueta, abacate, amêndoas doces, gérmen de trigo, girassol e semente de uva.

O conhecimento de uma diversidade maior de óleos e seus benefícios, amplia maiores possibilidades de uso e de técnicas de aplicação aos alunos; e aos professores, auxilia na didática de ensino-aprendizagem, em que é possível ainda, aplicar o conhecimento em prática. Aos alunos, especialmente, possibilita oferecer um serviço especializado e diferenciado na sua prática profissional futura.

\section{Biblioteca do Senac Saúde e Beleza}

O Senac Saúde e Beleza foi criado formalmente em 2007, como uma extensão da Faculdade de Tecnologia Senac em Florianópolis, e se tornou independente no final do mesmo ano, com a Resolução n. 14/07, ao qual passou a ser reconhecida como Centro de Educação Profissional, com autonomia de gestão de suas atividades e ações educacionais. Em 2009, altera o nome do espaço para Senac Saúde e Beleza, utilizado até hoje (GONÇALVES, 2014).

A biblioteca do Senac Saúde e Beleza é especializada nas áreas de saúde e de beleza e atende a cursos nos níveis de formação inicial continuada, técnico e tecnólogo. Tem como principal função dar suporte exclusivamente a essas duas áreas, tendo em vista que a instituição possui cursos relacionados a esse segmento. Porém, possui material de variadas áreas do conhecimento humano, possibilitando que os alunos busquem novos conhecimentos de seu interesse e não apenas os técnicos de sua área. Encontram-se também DVDs, banners e periódicos, para auxiliar no desenvolvimento de pesquisas e estudo dos alunos e na preparação e incremento nas aulas dos professores.

Com um acervo técnico atualizado, serve como fonte de pesquisa não apenas aos alunos, professores e colaboradores, mas também a toda comunidade em geral, que tem acesso irrestrito ao acervo, porém, não os possibilita empréstimo da coleção.

Desde sua criação, o corpo técnico que mantém a biblioteca atua de forma efetiva para auxiliar alunos e colaboradores na formação continuada, promovendo eventos, cursos de capacitação, treinamentos e ações socioculturais que beneficiem seu público alvo. Além do 
atendimento a empréstimos domiciliar e local, a biblioteca proporciona aos alunos o empréstimo entre as vinte e seis bibliotecas da rede Senac, que consiste em solicitar qualquer material que esteja em outra biblioteca além da unidade atuante, para que assim, os alunos usufruam de todo material que lhe é disponível para estudo.

Ademais, a biblioteca presta serviço de escâner, para que o aluno não precise sempre xerocar parte do livro, auxílio nas normas da ABNT, confecção de ficha catalográfica, levantamento bibliográfico, reserva de materiais, acesso à base de dados (como CAPES e EBSCO, que possuem artigos científicos reconhecidos mundialmente), além de disponibilizar espaço para estudo e pesquisa, com computadores e mesas para estudo coletivo.

Recentemente, a biblioteca conta com a aromateca, para auxílio na aprendizagem de alunos e professores, sendo também fonte de conhecimento e curiosidade aos colaboradores. Possui óleos essenciais e óleos vegetais para conhecimento olfativo, mas, que também podem ser utilizados em técnicas variadas para auxílio de dores musculares e dores no corpo em geral, procedimentos estéticos e no bem-estar. Desta maneira, a aromateca, auxilia na obtenção de conhecimento direto, e no ensino, aplicado à prática.

\section{3. Óleos essenciais}

Desde os primórdios, as plantas são utilizadas inteiramente, incluindo todos os seus elementos (raízes, folhas, flores e frutos), sendo consideradas desde então, altamente benéficas, com propriedades curativas. As plantas foram utilizadas como matéria prima para perfumes, fins medicinais, ritos de beleza, rituais religiosos - como iniciação na vida terrena ou para passagem para a vida além-túmulo. Esses fatos são evidenciados através de registros - nos mais variados suportes - advindos de regiões variadas no mundo, no qual é possível perceber a busca contínua por métodos que trouxessem benefícios físicos e espirituais, através de meios naturais, obtidos nas regiões onde residiam.

Os maiores registros advêm do Egito, Grécia, Roma e China, no qual é possível perceber a adoração pelos benefícios e os resultados que obtinham com a manipulação e extração das plantas, além de deixarem grandes legados conhecidos até hoje na área da aromaterapia (MAXWELL-HUDSON, 2000).

Apesar do uso dos óleos essenciais iniciar e repercutir nas antigas civilizações, o termo solidificado foi aparecer apenas no século XVI, introduzido por Paracelso (1494-1541). O 
termo "óleo" provém do termo árabe Az-zait que significa azeite e o termo "essencial" surgiu com os alquimistas, no qual acreditam que os óleos continham a "alma da planta" (SILVA, 2001).

O campo de estudo sobre os óleos essenciais obteve maiores conhecimentos a partir de alguns nomes na história, conhecidos como precursores da compreensão de que estes materiais naturais pudessem ser grandes aliados para cura e do bem-estar. Um destes nomes é o de Nicolas Culpeper, que publicou o livro Complete Herbal com inúmeras ervas medicinais e seus efeitos terapêuticos, conhecido até hoje pela área de aromaterapia. Assim como Culpeper, Gattefossé, em 1928, inicia seus trabalhos recuperando sua mão de uma grave queimadura com o uso do óleo essencial de lavanda. Gattefossé registrou seus feitos no seu livro Complexos naturais em dermatologia, iniciando o uso do termo "aromaterapia". Um pouco mais atual, Marguerite Muary, desenvolveu obras de referência sobre saúde, beleza, dietas e tratamentos, obtidos de seus conhecimentos combinados com a massagem ocidental com as propriedades medicinais dos óleos essenciais (CORAZZA, 2002).

Os óleos essenciais, por sua vez, são composições naturais, voláteis, que evaporam quando expostos ao ar, também chamados de óleos etéreos, constituídos a partir da extração de plantas aromáticas. Geralmente os óleos essenciais são diluídos em óleos vegetais, também chamados de carreadores, tendo como exemplo de utilização, as massagens. Mesmo que não se misturem com a água, podem ser utilizados em difusores para aromatização de ambientes e outros materiais.

De acordo com Amaral (2016), os efeitos dos óleos vegetais devem-se ao fato de possuir uma estrutura complexa, com características semelhantes ao éter e ao álcool. Por serem voláteis, não resvalam na pele diretamente. Neste caso, é indicado que se dilua os óleos essenciais em óleos vegetais ou em bases neutras cosméticas.

Os óleos essenciais podem ser orientados para pessoas que buscam terapias alternativas naturais, para alívio de dores, cura alternativa de doenças, tratamentos estéticos ou até mesmo para estimular habilidades como a criatividade, tranquilidade ou sensação de bem-estar. 


\section{Aplicabilidades, benefícios e contraindicações}

Os métodos para utilização dos óleos essenciais são variados e versáteis, nos quais dependem da necessidade expressa por parte do próprio indivíduo ou de indicações de um profissional. Cabe ressaltar que os óleos essenciais devem ser diluídos em óleos vegetais para sua utilização, devido sua alta concentração e também para melhor aderência na pele.

Comumente utilizados, os banhos aromáticos relaxantes, assim como as massagens terapêuticas, proporcionam sensações de satisfação e bem-estar, além de aliviar as tensões causadas e acumuladas no dia-a-dia. As massagens possuem maiores benefícios, pois estimulam diretamente a circulação sanguínea e linfática, proporcionando “[...] relaxamento, oxigenação e nutrição das células, além de desintoxicar o organismo e descarregar as tensões" (YWATA; ANTÔNIO; CORDEIRO, 2004, p. 37).

Amaral (2016), apresenta a possibilidade de compressas feitas em áreas externas que estejam doloridas, feridas, com cortes ou pontos cirúrgicos a fim de tratar. As compressas podem ser feitas quente, para tratamento de cólicas menstruais, torcicolos, dores em geral e espasmos musculares; ou compressas mornas para alívio de irritações, micoses e eczemas; e ainda, compressas frias, para melhora de inchaços, queimaduras - incluindo queimaduras solares -, cicatrizes, cortes e pós-cirúrgico.

Além das aplicações mencionadas acima, é possível amplificar a utilização em ambientes abertos, como no trabalho e em casa, com a utilização de difusores e aromatizadores de ambientes. Também é possível aplicar diretamente a um objeto, como travesseiros ou flanelas, para acalmar e tranquilizar quem o utilizar.

Os efeitos obtidos através do uso dos óleos podem ser alcançados diretamente, através da pele, da inalação/olfato e em alguns casos, na ingestão ou também, de forma indireta, por intermédio de difusores ou aromatizadores, alcançando e tratando problemas psíquicos e respiratórios, além de ativar competências como, a criatividade, o bem-estar, a tranquilidade e a concentração, em ambientes profissionais ou residenciais, podendo atingir um grupo maior de pessoas.

Os proventos do uso do óleo essencial expandem-se além do relaxamento e alívio provocados por massagens terapêuticas, que até mesmo podem tratar gorduras localizadas e celulites com o uso da técnica aliada aos poderes dos óleos. Estes benefícios estendem-se da 
cabeça aos pés, apresentado por Barros e Amaral (2004), os óleos essenciais auxiliam na resolução de problemas como de queda de cabelo, seborreia, piolhos, acne, mau hálito, afta, dor de dente, rinite e sinusite, torcicolo, intestino preso e intestino solto, assaduras em bebês, herpes, micoses de unhas, frieiras, dores em articulações e outros problemas, incluindo cuidados emocionais, como depressão, ansiedade, insônia e medo.

De forma geral, os óleos essenciais são utilitários para fins analgésicos, fungicidade e antiviral, antiinflamatório, antiespasmódico, anticatarral, equilibrante, descongestionante, cicatrizante, diurético, desintoxicante, digestivo, imunoestimulante, relaxante e sedativo (PRICE, 2014).

É de grande importância saber identificar e utilizar de maneira correta os óleos essenciais para não causar problemas graves aos receptores, tanto por meio de massagens terapêuticas, quanto pelo olfato direto ou da ingestão. Neste último caso, deve ser indicado apenas por profissionais qualificados. Para pessoas que possuam problemas graves de doenças, deve-se procurar um terapeuta com formação médica a fim de indicar se é possível realizar o tratamento através do uso de óleos essenciais e vegetais.

McGilvery et al. (1996) advertem que os óleos essenciais não devem ser aplicados diretamente à pele, sem diluição, por serem plantas com ativos altamente concentrados. Neste caso, é importante utilizar óleos carreadores para diluição dos mesmos. A utilização direta à pele pode causar alergia, manchas e lesões.

\section{Construção da Aromateca Saúde \& Beleza}

O termo "aromateca" é constituído da junção de duas palavras (aroma+teca) que caracterizam o significado da mesma, numa interpretação literal como "caixa de aromas". A palavra aroma denota do que é exalado de alguma substância vegetal e animal, também ligado ao sentido da área de aromaterapia. "Teca" advém da palavra biblioteca, que está relacionado a uma coleção de materiais, dispostos ordenadamente para acesso digital ou físico. Assim sendo, aromateca, nada mais é que uma biblioteca de aromas.

A aromateca caracteriza-se como um espaço físico destinado a um material singular, organizado de maneira técnica conforme as competências e habilidades de um bibliotecário, tornando assim o espaço especializado. A Aromateca Saúde e Beleza compõe-se de aromas, 
advindos de óleos essenciais e vegetais e possui a intenção de acrescentar no aprendizado de todos os indivíduos envolvidos e próximos a este espaço.

A iniciativa de criar uma aromateca de óleos essenciais partiu da necessidade de ter um acervo que pudesse auxiliar a prática profissional dos alunos. Desta forma, os mesmos podem ter acesso direto ao que estudam nos livros e socializam com os professores, "sentindo" a fonte de informação de forma concreta.

Com o objetivo definido e a intenção de concretizar o mais rápido possível o projeto, o próximo passo foi buscar apoio da direção da instituição, que prontamente deu seu aval positivo, entendendo que seria um grande benefício aos alunos. Em seguida, buscou-se parceria com empresas do ramo. O desafio foi conseguir amostras dos óleos com uma empresa que já era parceira do Senac e, em contrapartida, sua marca seria divulgada frente a um projeto de grande relevância. Como argumento positivo, foi preponderante também o fato de que possivelmente a iniciativa seria pioneira no Brasil, sendo a primeira aromateca de óleos essenciais em bibliotecas, fato que agrega ainda mais valor a iniciativa e pode se tornar um benchmaking ${ }^{1}$ para outras instituições que tenham cursos relacionados e usam os óleos em suas práticas.

A empresa contatada entendeu os benefícios que tal iniciativa poderia trazer para ambas as partes e aceitou o desafio de colocar em prática tal projeto. Inicialmente para compor o acervo derradeiro da aromateca foram doados 18 óleos essenciais e 8 óleos vegetais, os quais são os principais que a empresa comercializa no Brasil. Foi feita também a doação de um display, para melhor expor os óleos, e alguns manuais técnicos que explicam os benefícios de cada um e como eles podem ser usados. A figura 1 ilustra a montagem e estruturação da Aromateca Saúde \& Beleza no expositor disponibilizado pela empresa WNF.

\footnotetext{
${ }^{1}$ Técnica que visa identificar e analisar as melhores práticas do mercado, com vistas a futuras adaptações e implementações por parte das empresas utilizadoras de tais práticas (MARTINS; SANTOS; CARVALHO, 2015).
} 


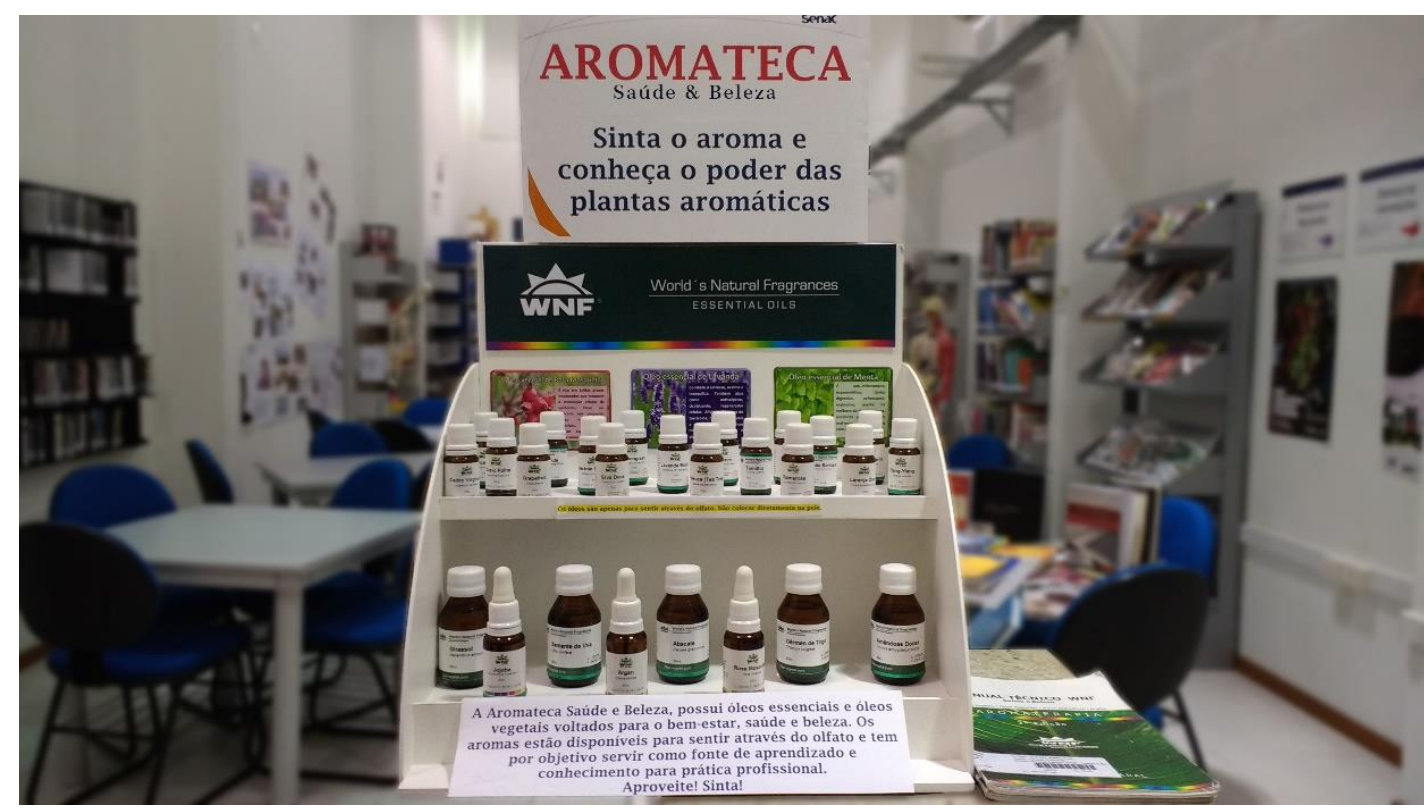

Figura 1 - Aromateca Saúde \& Beleza Fonte: autores (2017).

Os frascos receberam número de registro de exemplar, para que possam ser emprestados para uso em sala de aula e dispostos no display em ordem estabelecida de título dentro do Cutter.

No quadro 1 estão descritos os campos que foram utilizados no MARC21 para catalogação dos óleos. O software de gerenciamento de bibliotecas utilizado foi o Pergamum e a descrição do acervo completo encontra-se no catálogo coletivo da Rede de Bibliotecas do Senac/SC ${ }^{2}$.

${ }^{2}$ Acesso ao catálogo da Rede de Bibliotecas Senac/SC: http://pergamum.sc.senac.br/biblioteca/index.php InCID: R. Ci. Inf. e Doc., Ribeirão Preto, v. 8, n. 2, p. 192-204, set. 2017/fev. 2018. 
Quadro 1 - Campos do MARC da Aromateca

\begin{tabular}{|c|c|c|}
\hline CAMPO & DESCRIÇÃO & OBSERVAÇÃO \\
\hline Tipo de & 13- Artefato tridimensional ou realia & \\
\hline \multirow[t]{6}{*}{008} & $\begin{array}{l}\text { Primeira data: } 2016 \\
\text { Lugar de publicação: spb } \\
\text { Idioma: por } \\
\text { Público alvo: Especializada }\end{array}$ & $\begin{array}{l}\text { Somente preencher local onde foi produzido, ano de } \\
\text { fabricação, o idioma das informações contidas no frasco } \\
\text { e o público alvo. }\end{array}$ \\
\hline & 1 a 615.321 & (CDD padrão) - Medicamentos Fitoterápicos \\
\hline & 2 a 22 & Edição CDD \\
\hline & 1 d - Tipo & $\begin{array}{l}\text { Os tipos devem ser escritos pela sigla em caixa alta, que } \\
\text { são: Óleo Essencial (OLE) e Óleo Vegetal (OLV). }\end{array}$ \\
\hline & 2 a 615.321 & Medicamentos Fitoterápicos \\
\hline & 3 b W927a & $\begin{array}{l}\text { Entrar por W de "World's"* e letra inicial do nome de } \\
\text { óleo }\end{array}$ \\
\hline \multirow[t]{5}{*}{110} & WNF. World's Natural Fragrancies & \\
\hline & 1 a Nome & Nome que está em evidência no frasco \\
\hline & 3 c World's Natural Fragrancies & \\
\hline & Nome popular & $\begin{array}{l}\text { Começar o campo com } \quad \text { a } \quad \text { expressão } \\
\text { 'Nome popular:' e depois preencher o nome popular ou } \\
\text { variação de nome popular } \\
\end{array}$ \\
\hline & Nome científico & $\begin{array}{lllll}\text { Abrir outro campo 246, começar com a } & \text { a } \\
\text { expressão 'Nome científico:' e depois preencher } & \end{array}$ \\
\hline \multirow[t]{6}{*}{260} & 1 a Pinheiros, SP & Local de Fabricação dos óleos \\
\hline & 2 b World's Natural Fragrancies & Nome da fabricante ou produtor \\
\hline & 3 c 2016 & Ano de fabricação \\
\hline & 1 a 1 frasco de vidro & Descrever o item que armazena o produto \\
\hline & $2 \mathbf{b ~} 10 \mathrm{ml}$ & Descrever quantidade de óleo \\
\hline & $3 \mathrm{c} 6 \mathrm{~cm}$ & Descrever a altura do frasco \\
\hline 500 & & $\begin{array}{l}\text { Campo destinado para as notas explicativas. } \\
\text { Podem ser abertos quantos forem necessários, sendo } \\
\text { cada um deles para: } \\
\text { - Aspecto: aparência do óleo } \\
\text { - Nota olfativa: como seu aroma é percebido ou sentido }\end{array}$ \\
\hline 520 & & Resumo explicativo das principais funções do óleo \\
\hline \multirow[t]{2}{*}{650} & 1 a Aromateca & \\
\hline & $\begin{array}{l}\mathbf{2} \text { a Óleos Essenciais } \\
\mathbf{2} \text { a Óleos Vegetais }\end{array}$ & \\
\hline 651 & 1 a Brasil & Incluir país de origem do óleo \\
\hline
\end{tabular}

Fonte: autores (2017).

* World's Natural Fragrancies é empresa parceira do projeto que doou os óleos.

A figura 2 ilustra a catalogação pronta de um dos óleos essenciais que compõe a Aromateca Saúde \& Beleza. 


\begin{tabular}{|c|c|c|c|}
\hline 1 & & & 44828 \\
\hline 3 & & & BR-FISNA \\
\hline 5 & & & 20160906173300.0 \\
\hline 8 & & & 160906 s2016 spb\# \#\#\# \#00 0\#por\#d \\
\hline 82 & 0 & 4 & \$a $615.321 \$ 222$ \\
\hline 90 & & & Sd OLE Sa 615.321 Sb W927a \$8 10/ \\
\hline 110 & 2 & & Sa WNF. World's Natural Fragrancies \\
\hline 245 & 1 & 0 & Sa Alecrim/ Sc World's Natural Fragrancies \\
\hline 246 & 1 & 0 & Sa Nome popular: Alecrim \\
\hline 246 & 1 & 0 & Sa Nome cientifico: Rosmarinus Officinalis \\
\hline 260 & & & Sa Pinheiros, SP : Sb World's Natural Fragrancies, Sc 2016 \\
\hline 300 & & & Sa 1 frasco de vidro; \$b $10 \mathrm{ml} \$ \mathrm{c} 6 \mathrm{~cm}$ \\
\hline 500 & & & Sa Aspecto: Óleo transparente, incolor a levemente amarelado. \\
\hline 500 & & & Sa Nota olfativa: fresco, masculino, forte e dominante.. \\
\hline 520 & & & $\begin{array}{l}\text { Sa Atua sobre o sistema circulatório, músculos e articulações (excelente para alongamentos } \\
\text { musculares), estimulando a oxigenação. Fortalece a musculatura e a pele. Associado ao óleo } \\
\text { vegetal de Abacate ou Jojoba, no couro cabeludo, previne a queda dos cabelos.. }\end{array}$ \\
\hline 650 & 0 & 4 & Sa Aromateca \\
\hline 650 & 0 & 4 & Sa Óleos essenciais \\
\hline 651 & & 0 & Sa Brasil \\
\hline 930 & & & Sa 3000862625 Sb Sep 62016 5:32PM \\
\hline
\end{tabular}

Figura 2 - Catalogação de um óleo essencial Fonte: autores (2017).

Com a criação de um acervo especializado, é preciso pensar também na política de seleção e descarte destes materiais. Para tanto, o processo de seleção dos óleos essenciais e vegetais da Biblioteca Senac Saúde e Beleza, inicialmente, não é realizado de forma tão excludente, visto que os produtos recebidos vieram de empresa confiável e renomada na área. Com o planejamento de novas parcerias e de expansão do acervo, será efetivada uma política de seleção baseada nas necessidades de utilização dos cursos ofertados pelo Senac Saúde e Beleza, que utilizam dos materiais disponibilizados para seu processo de ensino-aprendizagem.

O descarte dos materiais será realizado quando os mesmos estiverem utilizados em sua totalidade pelos alunos e professores em sala de aula e nos procedimentos que auxiliem para a prática destes. Os frascos que acondicionam os óleos poderão ser enviados à WNF a fim de que 
os mesmos consigam reutilizá-los a outros fins, ou caso não seja oportuno, o descarte será feito através do lixo reciclável próprio para vidros. Apesar dos óleos apresentarem uma data de validade de 3 anos, pois a Anvisa estabelece um prazo de validade para revenda, os óleos são imperecíveis e desta forma podem ser usados em sua totalidade.

Considerando a alta relevância para prática e conhecimento dos alunos, tem-se a intenção de que o acervo cresça ainda mais, atribuindo novos óleos essenciais, diferentes dos já disponibilizados, por meio do fortalecimento da parceria já realizada e de novas parcerias com outras empresas do ramo, para que possam agregar conhecimento ao acervo já disponibilizado.

\section{Considerações finais}

A aromateca tem despertado o interesse cada vez maior das pessoas em conhecer este universo que para muitos ainda é desconhecido. Os benefícios dos óleos essenciais são variados e se usados de forma correta podem melhorar de forma significativa o bem-estar, saúde e beleza dos usuários.

A aromateca tem contribuído para as aulas, pois ao invés do professor apenas ilustrar os benefícios dos óleos para determinada prática, agora ele pode fazer o empréstimo na biblioteca e levar em sala de aula, de modo a possibilitar a vivência prática de seu uso e benefício. Isso possibilita um aprendizado maior aos estudantes, dinamiza as aulas e estabelece uma troca de experiências entre o corpo discente e docente.

Os relatos positivos de estudantes e colaboradores, demostra que o melhor caminho para formação profissional é poder dinamizar o aprendizado teórico com a prática, disponibilizando ferramentas e instrumentos que contribuam para aquisição de novos conhecimentos. Com a criação deste espaço, os óleos essenciais começaram a ser mais conhecidos por seus benefícios e compreendidos como uma fonte natural alternativa, para auxiliar no processo de recuperação e até de cura de problemas conhecidos no dia-a-dia, como estresse, dores musculares, dores de cabeça, entre outros.

Com a experiência de implantar tal projeto, fica a certeza de que se trata de algo inovador, que poderá servir de benchmarking para outras instituições, tendo em vista que não se tem registro de outra aromateca de óleos essenciais implantada em bibliotecas no Brasil. Outra certeza é de que será um valioso suporte informacional para o corpo docente, que poderá usar os óleos em suas aulas teóricas e práticas, e também para o corpo discente, que terá mais 
um suporte informacional para suprir suas necessidades e assim agregar mais valor em sua vivência acadêmica.

Sendo assim, espera-se que a aromateca, desperte novos interesses aos alunos na área da aromaterapia, uma vez que a intenção desta criação, é que os alunos atribuídos a educação por competências, possam aplicar na prática o uso dos óleos e que não se limitem à teoria. Além de possibilitar a expansão o campo de conhecimento e inserir novos aprendizados e novas formas de aplicação para solução de problemas tão já conhecidos no nosso dia-a-dia e que os profissionais, a partir deste conhecimento, poderão enriquecer em suas técnicas e aplicar aos seus clientes.

\section{Referências}

AMARAL, F. Manual técnico: bem estar, saúde e beleza: cuidados naturais da cabeça aos pés. 8. ed. [s.1.]: WNF, 2016.

BARROS, L. C.; AMARAL, F. Aromaterapia. São Paulo: Caras, 2004.

BOORHEM, R. L. Dicionário de medicina natural. Rio de Janeiro: Reader's Digest, 1997.

CORAZZA, S. Aromacologia: uma ciência de muitos cheiros. São Paulo: Senac Nacional, 2002.

GONÇALVES, J. S. (Org.). Nossa história é sua história: Senac Santa Catarina. Florianópolis: SENAC, 2014.

MARTINS, S. G.; SANTOS, A. S.; CARVALHO, L. M. O benchmarking e sua aplicabilidade em unidades de informação: uma abordagem reflexiva. Interface, Natal, v. 7, n. 1, p. 57-68, jan./ jun. 2015.

MAXWELL-HUDSON, C. Aromaterapia e massagem. São Paulo: Vitória Régia, 2000.

MCGILVERY, C. et al. Enciclopédia de aromaterapia, massagem e ioga. Erechim: Edelbra, 1996.

PRICE, S. Aromaterapia e as emoções: como usar óleos essenciais para equilibrar o corpo e a mente. 4. ed. Rio de Janeiro: Bertrand Brasil, 2014.

SILVA, A. R. Tudo sobre aromaterapia: como usá-la para melhorar sua saúde física, emocional e financeira. São Paulo: Roka, 2001.

YIN, R. K. Estudo de caso: planejamento e métodos. 4. ed. Porto Alegre: Bookman, 2010.

YWATA, C.; ANTÔNIO, J.; CORDEIRO, R. A cura está na natureza: medicina natural. São Paulo: Três, 2004. 